but as with the sulphuric reaction of vitamin $A$ fats, the reaction is one of frequent association rather than of identity.

The very complicated problems associated with the ætiology of rickets are still under investigation. Much of the older work was vitiated by failure to define exactly what changes were to be considered as rickets. Osteomalacia in adults and rickets in children appear to have a common cause, or at all events represent similar results, while osteoporosis is due to deficient new bone formation, or to resorption of old bone, Diagnosis should therefore be confirmed by $\mathrm{X}$-ray and histological examination. In the production of rickets, the essential factor is a lack of a vitamin which is similar to or identical with vitamin $\mathrm{A}$, and it is the young and growing individual who is especially sensitive to this deficiency. Given a restricted amount of this vitamin, the condition is greatly aggravated if there is a lack of calcium or phosphorus in the diet. or an improper balance between these two elements. The severest forms of rickets in man are often seer in the gloomy and smoke-enveloped industrial cities, and in this connexion it is especially interesting to learn that the onset of rickets is greatly retarded by exposure to sunlight or ultra-violet light of wavelength of $300 \mu \mu$ or less. It has even been claimed that contact with air which has been exposed to ultra-violet light accelerates the growth of rats fed on diets deficient in vitamin $\mathrm{A}$. Whether this be true or not, it appears that the favourable effects of ultraviolet radiation are due to a mobilising action which the light exerts on stores of fat-soluble vitamins in the body.

Whether the anti-rachitic vitamin is identical with vitamin A, appears somewhat doubtful. Though they exhibit certain similarities in their known properties, there are certain well-marked differences in distribution and in other of their properties. Sources of vitamin A which show an action in preventing rickets are not necessarily equally powerful in preventing xerophthalmia, which is regarded as a characteristic of this vitamin. This applies to such fats as butter and coco-nut oil, for example. As the technical difficulties in the way of quantitative determination of vitamin action are very considerable, it seems that no definite judgment on this point can as yet be given.

\title{
Chemistry at the British Empire Exhibition.
}

\section{(2) Heavy Chemicals.}

$\mathrm{I}^{\mathrm{N}}$ our previous article dealing with the chemical exhibits at the British Empire Exhibition, we gave some account of the situation and general arrangement of the Chemical Section in the Palace of Industry, and dealt with the fine chemicals and the scientific group. In the present article it is proposed to give a brief description of what may be termed the heavy chemicals.

Messrs. Brunner, Mond and Co., Ltd., and their allied companies, the Castner-Kellner Alkali Co., Ltd., Electro Bleach and By-Products Ltd., Chance and Hunt Ltd., Buxton Lime Firms Co., Ltd., and Synthetic Ammonia and Nitrates Ltd., have a large and impressive stand occupying more than $325^{\circ}$ square feet. In addition to their well-known "crescent products," including soda ash made by the ammonia soda process, bicarbonate of soda and ammonium salts, Messrs. Brunner, Mond are showing silicate of soda, one of the most interesting heavy chemicals, now finding an extensive use. Particularly is this the case for hardening concrete, and the stand includes an abrasion machine demonstrating by means of blocks of concrete, one half of which are treated with silicate of soda, the remarkable improvement of the properties by this process. Interesting also is a new form of calcium chloride in the form of crystals with the composition $\mathrm{CaCl}_{2} \cdot 2 \mathrm{H}_{2} \mathrm{O}$. The Castner-Kellner Alkali Co., Ltd., is showing many products obtained in the electrolysis of salt, including pure caustic soda, bleaching powder, liquid chlorine, and sodium peroxide, whilst Electro Bleach and By-Products Ltd. also has bleaching powder, soda crystals, and other products obtained by the Hargreaves-Bird process. Messrs. Chance and Hunt Ltd. display heavy chemicals, including acids, sodium sulphide, saltcake, and iron pigments, whilst the Buxton lime firms show lime and limestones, but particularly " Limbux," pure mechanically slaked lime, practically 100 per cent. $\mathrm{Ca}(\mathrm{OH})_{2}$. The exhibition of ammonia and ammonium salts by Synthetic Ammonia and Nitrates Ltd. shows that the synthetic ammonia works at Billingham-on-Tees is now in operation and is producing I00-1 20 tons of sulphate of ammonia per day.

The United Alkali Co., Ltd. is showing a whole range of products : bleaching powder, acids, and chemicals for all kinds of industries, particularly soap, paper, and glass manufacture, dyeing and calico-printing, aniline dyes, galvanising and agriculture; whilst Spencer Chapman and Messel Ltd. have an interesting exhibition of fuming sulphuric acid products, both sulphur trioxide crystals, and various standard acids with definite percentages of sulphur trioxide.

Coal tar and coal-tar products, together with intermediaries and the carbonisation of coal generally, are well represented. The South Metropolitan Gas Co. has an interesting stand, including acid-free sulphate of ammonia $\left(25.7\right.$ per cent. $\left.\mathrm{NH}_{3}\right)$, wood preservatives, and road tar to comply with the No. I specification of the Roads Department of the Ministry of Transport ; whilst the Gas Light and Coke Co., founded I I I years ago, shows not only a range of tar products but also $\beta$-naphthol and other intermediates, now a valuable section of the frrm's business developed since the War.

On the stand of Messrs. Burt, Boulton and Haywood Ltd. will be found particularly creosote for wood preservation, a business in which they have been engaged for sixty years, disinfectants, and especially colloidal sulphur, a valuable product for horticultural and veterinary work, and also in the manufacture of special soaps; whilst the Midland Tar Distillers Ltd. also displays a complete range of tar products.

As regards aniline dyes, British Dyes Ltd. has a very large stand, which gives satisfactory evidence of the great progress being made in the British dyestuff industry. This impression is confirmed also by the fine displays of various other companies not so well

$$
\text { No. } 2846 \text {, vol. I I } 3]
$$


known to the general public. Thus Scottish Dyes Ltd. shows a complete range of dyed and printed textiles, using their well-known anthraquinone vat colours for cotton and silk, and acid alizarine colours for wool, both of which are extremely fast to light; whilst Messrs. L. B. Halliday and Co., Ltd., have also devoted their space to proving conclusively that dyestuffs of their manufacture are equal to German and Swiss products, especially as regards fastness to light, many exposed dyeings being shown, prepared specially by the Huddersfield Chamber of Commerce.

Messrs. Hickson and Partners Ltd. indicate that they now manufacture an extensive list of dyestuffs and intermediate products, particularly such unusual products as ortho-anisidine and dichlor-aniline, together with sulphur colours, and roseine (magenta) with its allied products, such as soluble blues. Other British dyestuff firms. exhibiting are the Ajax Aniline-Dye Manufacturing Co.,Ltd., showing particularly specialties for the leather trade, Messrs. J. C. Bottomley and Emerson Ltd., the Clayton Aniline Co., Ltd., and Messrs. Williams Bros. and Co.

With regard to the application of dyestuffs, Messrs. B. Laporte Ltd. show all strengths of hydrogen peroxide, for both medicinal and toilet use, and for bleaching wool, silk, straw, and similar materials. Further, there is a range of barium compounds, sodium sulphide, sodium perborate, and laundry products.

Salt is well to the fore, particularly in relation to the Cheshire district, which has been the chief source of salt in Great Britain for the past two thousand years. Apart from the chemical industries, all varieties of table and ordinary salt used for the preparation of food, such as butter- and cheese-making, dairy work, baking and confectionery, and in the curing of fish, are shown. Much attention is given to the preparation of a "free-running" table salt for salt pourers. Prominent in this section are Murgatroyd's Salt Works, Chance and Hunt, and Electro Bleach and ByProducts Ltd.

As regards soap, the Erasmic Co., Ltd., have a very distinctive exhibit, especially toilet and shaving soaps, together with many toilet specialties; whilst Messrs. $D$. and W. Gibbs Ltd. show the manufacture with actual works plant of toilet soap, and Messrs. Joseph Watson Ltd. display their well-known products, especially "Matchless Cleanser," "Nubolic" disinfectant soap, together with the products of the firm's seed-crushing mills. Messrs. Lever Bros. Ltd. have a most extensive and interesting exhibit, including such well-known soaps as "Sunlight," "Lifebuoy," "Lux," and "Hudson's," together with "Twink" dyes and all kinds of toilet, shaving, and cleansing soaps, with many photographic illustrations of the famous Port Sunlight factory. Also to be noted are the products of the Ofome Companv and Messrs. J. J. Rigby Ltd.

Candles are well represented, a id Messrs. Price's Patent Candle Company, Ltd., are showing particularly the new "Trylite" triangular section candle, which is smokeless and does not gutter.

In the field of disinfectants we have Messrs. Newton, Chambers and Co., Ltd., with "Izal," Messrs. Jeyes Sanitary Compounds Ltd., "Jeyes fluid," the Midland Tar Distillers Ltd., and the South Metropolitan Gas Co. ; and as regards matches, Messrs. Bryant and May Ltd., who, with their associated companies in the overseas Dominions, are stated to turn out $\mathrm{I}, 000,000$ boxes of matches per 24 hours, have a particularly interesting exhibition, including not only every variety of their products and a model of their Fairfield Works at Bow, but also a unique collection from their private museum of " fire-striking " appliances.

Messrs. Peter Spence and Co., Ltd., have certainly one of the most beautiful stands of all, including a marvellous display of clear alum crystals of almost incredible perfection, including two pyramidal columns over 5 feet high, containing more than I3o perfect octahedral crystals of various sizes, the largest of which has taken two years to grow, whilst there is also a crystal more than $200 \mathrm{lb}$. in weight, the largest ever produced, the result of four years' growth. Very interesting also are the titanium specialties produced by this firm, which are largely used for stripping dyestuffs, and also in the leather industry.

Messrs. J. and J. White Ltd., the oldest and largest manufacturers of chrome salts in the world, have also a striking exhibit of their products, especially bichromates of potash and soda and various less-known salts, such as the trichromates, strontium chromate, and sesquioxide of chromium.

Finally, the Washington Chemical Co., Ltd., displays its well-known pure magnesia, of which it is the largest manufacturer in Europe. This product finds all kinds of uses, particularly in the form of 85 per cent. magnesia (mixed with 15 per cent. asbestos) as a high-grade nonconductive covering for steam-pipes and boilers, and for medicinal purposes.

\section{Obituary.}

MAJOR F. W. CRAGG, M.D., D.Sc.

'THE death of Major Francis William Cragg, from typhus, at Lahore, on April 23, came as a shock to his many friends and admirers. He was only forty-two years of age. Medical entomology has lost in him one of its ablest workers and the Indian Medical Service a distinguished officer.

Cragg graduated M.B., Ch.B. in 1905 at Edinburgh, and then entered the Indian Medical Service. In r9ro he came to Edinburgh on leave and attended Prof. Ashworth's class of medical entomology and parasitology, and under Prof. Ashworth's direction took up the study of insect morphology, paying particular

$$
\text { NO. } 2846 \text {, vol. I I } 3]
$$

attention to zoological technique. He graduated M.D. in I9II, and his thesis on "The Structure of Hcematopota pluvialis" was highly commended. This piece of research and the thorough grounding in technique was the foundation of Cragg's future work on medical entomology.

It was not long after his return to India before Cragg was drafted into the Bacteriological Department. The writer first made his acquaintance at the King Institute of Preventive Medicine, Guindy, Madras, where Cragg was sent to begin his scientific career, which was to prove so fruitful in so short a time. At Guindy, with much spare time and unlimited material, Cragg 